\title{
Characterization of lymph node metastasis and its clinical significance in the surgical treatment of gastric cancer
}

\author{
CHAO-HUI ZUO ${ }^{1}$, HAILONG XIE ${ }^{2}$, JINGSHI LIU ${ }^{1}$, XIAO-XIN QIU ${ }^{1}$, JIN-GUAN LIN ${ }^{1}$, XIAO HUA $^{1}$ and ANG QIN ${ }^{1}$ \\ ${ }^{1}$ Department of Gastroduodenal and Pancreatic Surgery, Hunan Provincial Tumor Hospital and Affiliated \\ Tumor Hospital of Xiangya School of Medicine, Central South University, Changsha, Hunan 410013; \\ ${ }^{2}$ Cancer Research Institute, University of South China, Hengyang, Hunan 421001, P.R. China
}

Received April 2, 2014; Accepted May 5, 2014

DOI: $10.3892 / \operatorname{mco} .2014 .303$

\begin{abstract}
This study aimed to characterize lymph node metastasis and determine its clinical significance in the surgical treatment of gastric cancer. The medical charts of 920 gastric cancer patients who underwent radical surgical resection between March, 2010 and March, 2013, were retrospectively reviewed and statistically analyzed. Lymphatic metastasis was observed in $69.6 \%$ of the patients (640/920). The frequency of lymph node metastasis in patients with early-stage gastric cancer was $21.4 \%$ (18/84). Lymph node metastasis was observed in all the patients with stage IIIC-IV gastric cancer. The incidence of lymph node metastasis was higher among patients with tumors $>7 \mathrm{~cm}$ in size. The most frequently affected lymph nodes in patients with proximal, central and distal gastric cancer were station no. 1 (34.2\%), no. $3(33.8 \%)$ and no. $6(34.3 \%)$ lymph nodes, respectively. The frequency of lymph node metastasis in patients with Borrmann type IV cancer was significantly higher compared to that in patients with other Borrmann type cancers. Our study further demonstrated that lymphatic metastasis is closely correlated with TNM stage, location, depth of invasion and size of gastric tumors. Therefore, we recommend that a sufficient number of lymph nodes be examined from each patient to determine the extent of lymph node dissection based on Borrmann type, location, size, depth of invasion and histology of the cancer.
\end{abstract}

\section{Introduction}

Gastric cancer is one of the most common cancers in several Asian countries, including China, South Korea and Japan, and

Correspondence to: Professor Chao-Hui Zuo, Department of Gastroduodenal and Pancreatic Surgery, Hunan Tumor Hospital and Affiliated Tumor Hospital, Xiangya School of Medicine, Central South University, 283 Tongzipo Road, Changsha, Hunan 410013, P.R. China

E-mail: zuochaohui@vip.sina.com

Key words: gastric cancer, lymphatic metastasis, gastrectomy, lymphadenectomy the second most common cause of cancer-related mortality worldwide $(1,2)$. China is among the countries with the highest incidence of gastric cancer, accounting for $>40 \%$ of all new cases worldwide $(1,2)$, with $\sim 470,000$ new patients diagnosed with gastric cancer annually. Approximately $75 \%$ of gastric cancer patients eventually succumb to the disease, making gastric cancer the third leading cause of cancer-related mortality $(1,3)$. Metastasis is a critical event affecting the prognosis of gastric cancer patients (4). The most common metastatic sites of gastric cancer are the lymph nodes, the peritoneal cavity and distant organs such as the liver, lungs and bone, through hematogenous metastasis. Lymph node metastasis is a well-established critical prognostic factor and predictor of gastric cancer recurrence (5-7). Therefore, extensive investigation of lymphatic metastasis is likely to increase our understanding of the metastatic mechanisms and improve the effectiveness of surgical treatment of gastric cancer patients (8-11).

We have systematically investigated the characteristics of lymphatic metastasis in gastric cancer and obtained valuable experience regarding cancer management. In this study, we retrospectively reviewed the medical charts of 920 gastric cancer patients who underwent radical surgical resection in our department between March, 2010 and March, 2013.

\section{Patients and methods}

Patient information. Between March, 2010 and March, 2013, a total of 920 patients with pathologically diagnosed gastric cancer (601 men and 319 women, with a mean age of 51 years) were admitted to our hospital and underwent standard D2 radical gastrectomy without preoperative neoadjuvant chemotherapy. Among these patients, 84 were diagnosed with early-stage cancer, defined as invasive carcinoma confined to the mucosa and/or submucosa, with or without lymph node metastases, irrespective of the tumor size. The remaining patients were diagnosed with advanced gastric cancer that invaded the muscularis propria (MP) or beyond $(12,13)$. With regard to the location of the primary tumor, 99 were located in the upper third of the stomach (U), 158 in the middle third (M), 576 in the lower third (L) and 87 affected the entire stomach (LMU). The levels of tumor-associated antigens, including carcinoembryonic antigen, cancer antigen 19-9 
Table I. Correlation between TNM stage and lymph node metastasis.

Distribution of lymph node metastasis

\begin{tabular}{lcccc}
$\begin{array}{l}\text { TNM } \\
\text { stage }\end{array}$ & $\begin{array}{c}\text { Patient } \\
\text { no. }\end{array}$ & $\begin{array}{c}\text { No. of patients with lymph } \\
\text { node metastasis }(\%)^{\mathrm{a}}\end{array}$ & $\begin{array}{c}\text { Total no. of excised } \\
\text { lymph nodes }\end{array}$ & $\begin{array}{c}\text { No. of affected } \\
\text { lymph nodes }(\%)^{\mathrm{b}}\end{array}$ \\
\hline IA & 62 & $0(0.00)$ & 168 & 0 \\
IB & 36 & $6(11.1)$ & $7.00)$ \\
IIA & 42 & $7(16.7)$ & 910 & $4(0.7)$ \\
IIB & 51 & $11(21.6)$ & 1,336 & $70(7.7)$ \\
IIIA & 190 & $81(42.3)$ & 4,380 & $99(8.8)$ \\
IIIB & 229 & $225(98.3)$ & 5,935 & $420(9.6)$ \\
IIIC & 130 & $130(100.0)$ & 3,350 & $1,267(21.3)$ \\
IV & 180 & $180(100.0)$ & 4,637 & $1,010(30.2)$ \\
Sum & 920 & $640(69.57)$ & 21,436 & $1,610(34.7)$ \\
\end{tabular}

${ }^{\mathrm{a} B y}$ TNM stage $\chi^{2}=61.864, \mathrm{P}<0.001 .{ }^{\mathrm{b}} \mathrm{By}$ TNM stage $\chi^{2}=62.296, \mathrm{P}<0.01$.

and $\alpha$-fetoprotein were also measured preoperatively in the sera of the patients.

Distant metastases to the liver, lung and peritoneum were not found in these patients. A total of 596 patients underwent distal partial gastrectomy, 284 underwent gastrectomy and 40 were subjected to proximal partial gastrectomy. According to the Borrmann gross classification, 67, 155, 611 and 87 gastric cancers were classified as type I, II, III and VI, respectively. The patients were not administered chemotherapy preoperatively.

Surgical procedure. An upper abdominal midline incision extending from the xiphoid process to the umbilicus was performed to expose the abdomen and the exposure of the upper abdomen was further enhanced by traction. The Kocher's incision outboard of the duodenum was routinely employed to completely isolate and mobilize the duodenum, and to detect whether the lymph nodes of stations no. 13 and 16 were affected. The extent of regional lymph node resection for any given patient was determined by the size and location of the cancer. Routinely, the greater omentum, the anterior lobe of the transverse mesocolon and the pancreatic capsule were incised. The distance between the incision line and the outer edge of the cancer was determined by Borrmann type and was found to be $\sim 4-7 \mathrm{~cm}$. The distance in the case of Borrmann type I, II, III and IV cancer is 2, 3-4, 5-6 and 6-7 cm, respectively.

Roux-en-Y esophagojejunostomy was used for the reconstruction of the alimentary tract following gastrectomy. Billroth's operations I and II were used for the reconstruction of the alimentary tract following distal partial gastrectomy in 470 and 126 cases, respectively. The majority of the patients (80.2\%; 738/920) were subjected to postoperative chemotherapy and $18.6 \%(171 / 920)$ patients were subjected to postoperative radiotherapy. In total, 30, 590, 180 and 120 patients were subjected to D1, D2, D2 ${ }^{+}$and $\mathrm{D} 3$ resection, respectively.

Pathological analysis. Gastric cancer specimen processing, pathological diagnosis, assessment of diagnostic criteria and lymph node classification were performed based on the
Japanese gastric cancer treatment protocols (14). According to the pathological TNM staging standards (15), pathological tumor ( $\mathrm{pT}$ ) and pathological node (pN) classifications were used to define the metastases of perigastric lymph node stations no. 1-16.

Statistical analysis. SPSS 17.0 statistical software (SPSS Inc., Chicago, IL, USA) was used for data processing. The Chi-square and t-tests were used to analyze the correlation between pathological characteristics, such as invasion depth and lymph node metastasis.

\section{Results}

Pathological type, TNM stage and lymph node metastasis. Among the 920 patients, 495 were diagnosed with adenocarcinoma, including 278 cases of poorly differentiated, 139 cases of moderately differentiated and 78 cases of well-differentiated adenocarcinoma. A total of 208 patients were diagnosed with signet ring cell carcinoma, 109 with mucinous adenocarcinoma, 39 with undifferentiated carcinoma, 49 with adenosquamous carcinoma and 20 with squamous cell carcinoma. Among the 130 patients who were preoperatively treated with neoadjuvant chemotherapy, 21 were tumor regression grade (TRG) 0 , whereas $31,41,26$ and 11 patients were TRG 1 , 2, 3 and 4, respectively. As regards TNM stage (14), 62 cases were stage IA, 36 were stage IB, 42 were stage IIA, 51 were stage IIB, 190 were stage IIIA, 229 were stage IIIB, 130 were stage IIIC and 180 cases were stage IV. The number of affected lymph nodes and the frequency of patients positive for lymph node metastasis were positively correlated with TNM stage. Generally, the more advanced the stage, the higher the metastatic rate $(\mathrm{P}<0.05)$. The frequency of lymph node metastasis among patients with stage IIIC-IV gastric cancer was $100 \%$ and the percentage of affected lymph nodes was $30-40 \%$. The details of lymph node metastasis are summarized in Table I.

Lymph node metastasis in gastric cancer. Lymph node metastases were detected in $69.6 \%$ (640/920) of the patients, while 
Table II. Correlation between gastric cancer diameter and lymph node metastasis.

Distribution of lymph node metastasis

\begin{tabular}{|c|c|c|c|c|c|}
\hline $\begin{array}{l}\text { Diameter } \\
(\mathrm{cm})\end{array}$ & $\begin{array}{c}\text { Patient } \\
\text { no. }\end{array}$ & $\begin{array}{l}\text { No. of patients with lymph } \\
\text { node metastasis }(\%)^{\mathrm{a}}\end{array}$ & $\begin{array}{l}\text { Total no. of excised } \\
\text { lymph nodes }\end{array}$ & $\begin{array}{l}\text { Average excised } \\
\text { lymph nodes }\end{array}$ & $\begin{array}{c}\text { No. of affected } \\
\text { lymph nodes }(\%)^{\mathrm{b}}\end{array}$ \\
\hline$<3$ & 110 & $(23.6)$ & 2,040 & 18.6 & $160(7.8)$ \\
\hline $3-5$ & 285 & $185 \quad(64.9)$ & 5,810 & 20.4 & $1,158 \quad(19.9)$ \\
\hline $5-7$ & 315 & $252 \quad(80.0)$ & 6,920 & 22.0 & $1,500 \quad(21.7)$ \\
\hline$>7$ & 210 & $177 \quad(84.3)$ & 6,666 & 31.7 & $1,662(24.9)$ \\
\hline Sum & 920 & $640 \quad(69.6)$ & 21,436 & 23.3 & $4,480 \quad(20.9)$ \\
\hline
\end{tabular}

${ }^{\mathrm{a} B y}$ tumor diameter $\chi^{2}=12.864, \mathrm{P}<0.05 ; .{ }^{\mathrm{b}} \mathrm{By} \mathrm{TNM}$ stage $\chi^{2}=12.538, \mathrm{P}<0.05$.

$20.9 \%(4,480 / 21,436)$ of the examined lymph nodes were positive for metastasis. An average of 6 lymph nodes were affected in each patient. Among the 84 patients with early-stage gastric cancer, 62 were stage IA, 16 were stage IB, 4 were stage IIA and 2 were stage IIB $(12,13)$. Lymph node metastases occurred in $21.3 \%(18 / 62)$ of these patients. Lymph node metastases were observed in $74.4 \%$ (622) of the 836 patients with advanced gastric cancer. The rate of lymph node metastasis was positively correlated with the diameter of the tumor. Lymph node metastases were observed in $15.0 \%$ (3/20) patients with carcinoma confined to the mucosa, whereas lymph node metastases were detected in $23.4 \%(15 / 64), 48.2 \%$ (52/108), and 69.8\% (280/358) of patients with carcinoma invading the submucosa (SM), MP and serous layer, respectively. Approximately 75.7\% (212/280) of the patients with gastric cancer that had invaded or broken through the serosa but had not spread to other organs and $86.7 \%$ (78/90) of the patients with gastric cancer that had already metastasized to other organs were positive for lymph node metastases. The extent of the affected lymph nodes for a given patient was positively correlated with the depth of cancer invasion. For example, in 3 patients with cancer confined to the mucosa, only the lymph nodes of station no. 1 were affected; in 15 cases with cancer invading the SM, the lymph nodes of station no. 1 were invaded in 8 patients and the lymph nodes of station no. 2 were affected in 7 patients. Tumor size was significantly correlated with perigastric lymph node metastasis. In patients with a tumor size of $>3 \mathrm{~cm}$, the incidence of lymph node metastasis was significantly lower compared to that in patients with tumors $<3 \mathrm{~cm}$ in diameter $(\mathrm{P}<0.05)$. The details of the distribution of lymph node metastasis are listed in Table II.

Correlation between perigastric lymph node metastasis and cancer location. The extent of lymph node metastasis in gastric cancer differed according to location in various parts of the stomach. The frequency of the affected lymph node stations was as follows: no. $1,34.3 \%$; no. $3,29.3 \%$; no. $2,23.2 \%$; and no. $7,20.2 \%$ in patients with U gastric cancer; no. 3, 33.5\%; no. $4 \mathrm{sb}, 21.5 \%$; no. $7,20.3 \%$; and no. $1,18.4 \%$ in patients with M gastric cancer; no. 6, 34.0\%; no. 3, 33.0\%; no. 4d, 30.0\%; and no. $7,25.3 \%$ in patients with $\mathrm{L}$ gastric cancer; and no. $3,48.3 \%$; no. 4 d, $30.0 \%$; no. $6,26.4 \%$; and no. $7,26.4 \%$ in patients with LMU gastric cancer. The details are summarized in Table III.
Correlation of lymph node metastasis with Borrmann type and extent of lymph node dissection. The radical dissection method was determined based on preoperative staging and intraoperative assessment. Lymph node metastases were identified in $20.0 \%$ of the 30 patients who underwent D1 radical excision. An average of 18 (540/30) lymph nodes were excised from each of these patients and $10.0 \%$ (54/540) of the excised lymph nodes were positive for metastasis. Lymph node metastases were identified in $58.3 \%$ (350/590) of the patients who underwent D2 radical excision. An average of $20.8(12,290 / 590)$ lymph nodes were excised from each of these patients and $18.0 \%(2,213 / 12,290)$ of the excised lymph nodes were positive for metastasis. While lymph node metastases were identified in $92.2 \%$ (166/180) of the patients who underwent $\mathrm{D} 2^{+}$radical excision, an average of $24(4,320 / 180)$ lymph nodes were excised from each patient and $23.4 \%(1,011 / 4,320)$ of the excised lymph nodes were affected. Lymph node metastasis was identified in $98.3 \%(118 / 120)$ of the patients who underwent $\mathrm{D} 2^{+}$radical excision. An average of $26.6(3,186 / 120)$ lymph nodes were excised from each patient and $34.6 \%(1,102 / 3,186)$ of the excised lymph nodes were affected. The number and rate of affected lymph nodes were the highest among patients with Borrmann IV cancer. The details of the affected lymph nodes for each Borrmann type are listed in Table IV.

\section{Discussion}

The most common sites of distant spread of gastric cancer are the regional lymph nodes. The stomach has a very rich network of lymph vessels and nodes. Over the last few years, it has been demonstrated that the number of removed lymph nodes in radical gastrectomy for gastric cancer is closely correlated with the patients' survival rate. Seevaratnam et al (10) reported that the number of removed lymph nodes was positively correlated with the patient's survival rate and demonstrated that patients with stage T1-T2 cancer, from whom 15 lymph nodes were removed, or patients with stage T3-T4 cancer, from whom 20 lymph nodes were removed, exhibited significantly higher survival rates compared to those of patients with cancer of identical stage from whom less lymph nodes were removed $(\mathrm{P}<0.05)$. That study concluded that the number of removed lymph nodes was an independent prognostic factor. 
Table III. Lymph node metastasis according to gastric cancer location.

\begin{tabular}{|c|c|c|c|c|c|}
\hline \multirow{2}{*}{$\begin{array}{l}\text { Lymph } \\
\text { node } \\
\text { station (no.) }\end{array}$} & \multicolumn{5}{|c|}{ Lymph node metastases } \\
\hline & $\begin{array}{c}\mathrm{L}, \text { no. }(\%) \\
(\mathrm{n}=576)\end{array}$ & $\begin{array}{c}\text { M, no. }(\%) \\
(\mathrm{n}=158)\end{array}$ & $\begin{array}{l}\text { U, no. }(\%) \\
(\mathrm{n}=99)\end{array}$ & $\begin{array}{l}\text { LMU, no. }(\%) \\
\quad(\mathrm{n}=87)\end{array}$ & $\begin{array}{l}\text { Total, no. }(\%) \\
\quad(\mathrm{n}=920)\end{array}$ \\
\hline 1 & 35 & $29(18.4)$ & $34 \quad(34.3)$ & $22(25.3)$ & $120(13.0)$ \\
\hline 2 & $6(1.0)$ & $7 \quad(4.4)$ & $23(23.2)$ & $3(3.5)$ & $39(4.2)$ \\
\hline 3 & $190(33.0)$ & $53 \quad(33.5)$ & $29(29.3)$ & $42(48.3)$ & $314(34.1)$ \\
\hline $4 \mathrm{sa}$ & $0 \quad(0.0)$ & $15(9.5)$ & $10(10.1)$ & $1(1.2)$ & $26(2.8)$ \\
\hline $4 \mathrm{sb}$ & $139(24.1)$ & $34(21.5)$ & $6(6.1)$ & $21(24.1)$ & $200(21.7)$ \\
\hline $4 d$ & $173(30.0)$ & 31 (19.6) & $4(4.0)$ & $33(37.9)$ & $241(26.2)$ \\
\hline 5 & $115(20.0)$ & $13(8.2)$ & $2(2.0)$ & $20(23.0)$ & $150(16.3)$ \\
\hline 6 & $196(34.0)$ & $22(13.9)$ & $2(2.0)$ & $23(26.4)$ & $243(26.4)$ \\
\hline 7 & $127(22.0)$ & $32(20.3)$ & $20(20.2)$ & $22(25.3)$ & $201(21.9)$ \\
\hline $8 a$ & $99(17.2)$ & $19(12.0)$ & $5(5.1)$ & $12(13.9)$ & $135(14.7)$ \\
\hline $8 p$ & $50(8.7)$ & $8(5.1)$ & $2(2.0)$ & $6(6.9)$ & $66(7.2)$ \\
\hline 9 & $21(3.7)$ & $8(5.1)$ & $6(6.1)$ & $7(8.1)$ & $42(4.6)$ \\
\hline 10 & $2(0.4)$ & $7(4.4)$ & $3(3.0)$ & $8(9.2)$ & $20(2.2)$ \\
\hline $11 \mathrm{p}$ & $24 \quad(4.2)$ & $16(10.1)$ & $7(7.1)$ & $4(4.6)$ & $51(5.5)$ \\
\hline $11 \mathrm{~d}$ & 10 & $9(5.7)$ & $4(4.0)$ & $3(3.5)$ & $26(2.8)$ \\
\hline $12 \mathrm{a}$ & $60(10.4)$ & $9(5.7)$ & $1(1.0)$ & $1(1.2)$ & $71(7.7)$ \\
\hline $12 \mathrm{p}$ & $15(2.6)$ & $5(3.2)$ & $1(1.0)$ & $1(1.2)$ & $22(2.4)$ \\
\hline $12 \mathrm{~b}$ & $9(1.6)$ & $0 \quad(0.0)$ & $\begin{array}{ll}0 & (0.0)\end{array}$ & $0 \quad(0.0)$ & $9(1.0)$ \\
\hline $12 \mathrm{~h}$ & $1(0.2)$ & $0 \quad(0.0)$ & $\begin{array}{ll}0 & (0.0)\end{array}$ & $0 \quad(0.0)$ & $1(0.1)$ \\
\hline 13 & $14(2.4)$ & $3(1.9)$ & $0 \quad(0.0)$ & $1(1.2)$ & $18(2.0)$ \\
\hline $14 \mathrm{v}$ & $4(0.7)$ & $1 \quad(0.6)$ & $\begin{array}{ll}0 & (0.0)\end{array}$ & $2(2.3)$ & $7(0.8)$ \\
\hline 15 & $6(1.0)$ & $4 \quad(2.5)$ & $\begin{array}{ll}0 & (0.0)\end{array}$ & $1(1.2)$ & $11(1.2)$ \\
\hline $16 \mathrm{a} 2$ & $6(1.0)$ & $2(1.3)$ & $1(1.0)$ & $3(3.5)$ & $12(1.3)$ \\
\hline
\end{tabular}

L, cancer of the lower third of the stomach; M, cancer of the middle third of the stomach; U, cancer of the upper third of the stomach; LMU, cancer spreading to the entire stomach.

Table IV. Correlation between Borrmann type and lymph node metastasis.

Distribution of lymph node metastasis

\begin{tabular}{|c|c|c|c|c|}
\hline \multirow[b]{2}{*}{$\begin{array}{l}\text { Borrmann } \\
\text { Type }\end{array}$} & \multirow[b]{2}{*}{ Patient no. } & \\
\hline & & $\begin{array}{l}\text { No. of patients with lymph } \\
\text { node metastasis }(\%)^{\mathrm{a}}\end{array}$ & $\begin{array}{l}\text { Total excised } \\
\text { lymph nodes }\end{array}$ & $\begin{array}{l}\text { Average excised } \\
\text { lymph nodes }(\%)\end{array}$ \\
\hline I & 67 & $15(22.4)$ & 1,513 & 228 \\
\hline II & 155 & $79(51.0)$ & 3,572 & $643(18.0)$ \\
\hline III & 611 & 468 (76.6) & 14,479 & $3,038 \quad(21.0)$ \\
\hline IV & 87 & 78 (89.7) & 1,872 & $591(30.5)$ \\
\hline Sum & 920 & $640 \quad(69.6)$ & 21,436 & $4,480 \quad(20.1)$ \\
\hline
\end{tabular}

${ }^{\mathrm{a} B y}$ Borrmann type $\chi^{2}=9.271, \mathrm{P}<0.05$. ${ }^{\mathrm{b}} \mathrm{By}$ Borrmann type $\chi^{2}=8.705, \mathrm{P}<0.05$.

The incidence and extent of lymph node metastasis were found to be closely correlated with the degree of malignancy and location of gastric cancer. Lee et al (16) demonstrated that lymph node metastasis was closely associated with TNM stage and the biological characteristics of gastric cancer. In this study, we also demonstrated that lymph node metastasis in gastric cancer is closely correlated with TNM stage, depth of invasion, size, location and Borrmann type. The incidence and extent of lymph node metastasis are positively correlated with TNM stage. For example, the incidence of lymph node metastasis for patients with stage IIIB, IIIC and IV gastric cancer were $\sim 100 \%$, whereas that for patients with stage I 
gastric cancer was $<10 \%$. We also observed that lymph node metastasis in gastric cancer was positively correlated with the depth of invasion. For example, the incidence of lymph node metastasis for gastric cancer within the serosa and gastric cancer spreading to adjacent organs was 75.7 and $86.7 \%$, respectively. Wang et al (17) also reported that the incidence of lymph node metastasis of gastric cancer was positively correlated with TNM stage, suggesting that the more advanced the TNM stage, the higher the incidence of lymph node metastasis. $\mathrm{Xu}$ et al (11) recently demonstrated that neither the metastatic lymph node ratio nor the log odds of positive lymph nodes reduced the staging bias and concluded that a sufficient number of examined lymph nodes was required to ensure an accurate prognosis for patients undergoing D2 radical gastrectomy.

Wang et al (18) demonstrated that the size of $\mathrm{L}$ gastric cancer was positively correlated with the incidence of lymph node metastasis and observed that the incidence of lymph node metastasis in patients with a cancer size of $>4.8 \mathrm{~cm}$ was higher compared to that in patients with a cancer size of $<4.8 \mathrm{~cm}$. Our study also demonstrated that patients with large-sized cancers exhibited a higher incidence of lymph node metastasis. The incidence of lymph node metastasis in patients with a cancer size of $3-5 \mathrm{~cm}$ was $64.9 \%$, whereas that in patients with a cancer size of $5-7 \mathrm{~cm}$ was $80.0 \%$. The percentage of affected lymph nodes was 19.9 and $21.67 \%$ in these two groups of patients, respectively. The incidence of lymph node metastasis in patients with a cancer size of $>7 \mathrm{~cm}$ was $84.3 \%$, with a percentage of affected lymph nodes of $24.9 \%$.

Tokunaga et al (19) indicated that lymph node metastasis in gastric cancer usually spreads from the proximal to the distal lymph nodes by way of the lymphatic drainage. The U lymphatic drainage mainly flows through the left gastric artery, posterior gastric artery and splenic artery. The L lymphatic drainage goes along the common hepatic and superior mesenteric arteries. The $\mathrm{M}$ lymphatic drainage has the characteristics of both $\mathrm{U}$ and $\mathrm{L}$. The perigastric lymphatic drainages eventually flow into the lymph nodes surrounding the abdominal aorta. That study also reported that the characteristics of lymph node metastasis in gastric cancer generally follow the way of lymphatic drainage, which is consistent with previously reported findings (20). Several studies demonstrated that, for advanced gastric cancer, D2 dissection may significantly improve the patients' survival rate, whereas the number of removed lymph nodes is also significantly correlated with prognosis $(21,22)$. In this study, the incidence of lymph node metastasis was positively correlated with the type of lymph node dissection. For patients with early and advanced gastric cancer positive for lymph node metastasis, regional lymph node dissection should not be confined to D1; instead, D2, D2 ${ }^{+}$or D3 should be adopted (23). In this study, we also demonstrated that patients with Borrmann type IV gastric cancer had the highest incidence and extent of lymph node metastasis, which is consistent with previous reports (24).

Our study demonstrated that metastasis in station no. 2 lymph nodes from distal gastric cancer was only $1.0 \%$ and we observed that metastasis in station no. 4 lymph nodes was $>20 \%$. Han et al (20) reported that the incidence of metastasis in station no. 4 lymph nodes in patients with proximal gastric cancer was $\sim 12.6 \%$. A previous study also demonstrated that the frequency of metastasis in station no. $4 \mathrm{~d}, 5$ and 6 lymph nodes in patients with proximal gastric cancer was $>10.0 \%$ (24). It was also demonstrated that the majority of proximal gastric cancers are middle- or late-stage cancers $(26,27)$. We consider that radical resection of splenic hilar lymph nodes is required for proximal but not for distal gastric cancer, as previously proposed $(28,29)$. Since station no. 11 p is immediately adjacent to stations no. 7 and 9 , in the case of distal gastric cancer, station no. 11 should be preserved; however, for proximal gastric cancer, both no. 11p and 11d stations should be removed. The lymph nodes around the splenic artery are important to the splenic artery and its function (30). With the advances in surgical techniques, it is feasible to protect the spleen during lymph node resection.

It was previously reported that, for advanced proximal gastric cancer, the incidence of metastasis in no. 10 station lymph nodes was $9.8-20.9 \%(31,32)$. We also observed that the incidence of lymph node metastasis was $11.2 \%$ for proximal gastric cancer, whereas that for distal gastric cancers was $<1 \%$. The incidence of metastasis in no. 12 station lymph nodes is high and there is no clear anatomical boundary between stations no. $12 \mathrm{a}$ and $12 \mathrm{p}$. For patients with distal gastric cancer that has already spread to the pylorus or broken through the serosa, the hepatic artery proper and the bile duct should be suspended to maintain a good circulation in the porta hepatis. Theoretically, the lymphatic drainage of stations no. $14 \mathrm{v}$ and 15 belong to the lymphatic drainage of the colon; metastasis in these lymph nodes is rare and is considered as distant metastasis. According to the Japanese gastric cancer treatment Statute, version 14 (14), these lymph nodes should be included in D2 lymph node dissection. However, as station no. $14 \mathrm{v}$ is closely adjacent to station no. 6 , if there is suspicion of metastasis to the lymph nodes station in no. 6 , station no. 14 lymph nodes should also be removed. Although the curative effect of station no. 16 lymph node dissection awaits further evaluation, in the case of advanced gastric cancer, D2 lymph node dissection plus resection of station no. 16 lymph nodes may improve the curative effect without increasing the risk of complications and mortality.

In summary, lymph node metastasis in gastric cancer exhibits unique characteristics. The extent of lymph node dissection for any given patient should be carefully selected based on Borrmann type, location, size, depth of invasion and histological type of the cancer.

\section{Acknowledgements}

This study was supported by the Hunan Provincial Public Health Department (grant no. B2013101), P.R. China.

\section{References}

1. Peng $\mathrm{J}$ and Wang Y: Epidemiology, pathology and clinical management of multiple gastric cancers: a mini-review. Surg Oncol 19: e110-e114, 2010.

2. Jemal A, Bray F, Center MM, Ferlay J, Ward E and Forman D: Global cancer statistics. CA Cancer J Clin 61: 69-90, 2011.

3. Wu Y, Fan Y, Jiang Y, Wang Y, Liu H and Wei M: Analysis of risk factors associated with precancerous lesion of gastric cancer in patients from eastern China: a comparative study. J Cancer Res Ther 9: 205-209, 2013.

4. Bedikian AY, Chen TT, Khankhanian N, et al: The natural history of gastric cancer and prognostic factors influencing survival. J Clin Oncol 2: 305-310, 1984. 
5. Saka M, Katai H, Fukagawa T, Nijjar R and Sano T: Recurrence in early gastric cancer with lymph node metastasis. Gastric Cancer 11: 214-218, 2008

6. Kunisaki C, Akiyama H, Nomura M, et al: Surgical outcomes for early gastric cancer in the upper third of the stomach. J Am Coll Surg 200: 15-19, 2005.

7. Ikeda Y, Saku M, Kishihara F and Maehara Y: Effective follow-up for recurrence or a second primary cancer in patients with early gastric cancer. Br J Surg 92: 235-239, 2005.

8. Takagane A, Terashima M, Abe K, et al: Evaluation of the ratio of lymph node metastasis as a prognostic factor in patients with gastric cancer. Gastric Cancer 2: 122-128, 1999.

9. Bando E, Yonemura Y, Taniguchi K, Fushida S, Fujimura T and Miwa K: Outcome of ratio of lymph node metastasis in gastric carcinoma. Ann Surg Oncol 9: 775-784, 2002.

10. Seevaratnam R, Bocicariu A, Cardoso R, et al: How many lymph nodes should be assessed in patients with gastric cancer? A systematic review. Gastric Cancer 15 (Suppl 1): S70-S88, 2012.

11. Xu J, Bian YH, Jin X and Cao H: Prognostic assessment of different metastatic lymph node staging methods for gastric cancer after D2 resection. World J Gastroenterol 19: 1975-1983, 2013.

12. Adachi Y: Definition of early gastric cancer and Dukes's A tumor. J Am Coll Surg 186: 605-606, 1998.

13. Saragoni L, Morgagni P, Gardini A, et al: Early gastric cancer: diagnosis, staging, and clinical impact. Evaluation of 530 patients. New elements for an updated definition and classification. Gastric Cancer 16: 549-554, 2013.

14. Tsuburaya A, Hayashi T, Yoshikawa T: Points of revision in the new Japanese treatment guidelines for gastric cancer. Nihon Rinsho 70: 1758-1762, 2012 (In Japaneese).

15. Sobin LH, Gospodarowicz M and Wittekind C (eds): TNM Classification of Malignant Tumors. Wiley-Blackwell, Oxford, 2009.

16. Lee SR, Kim HO, Son BH, Shin JH and Yoo CH: Prognostic significance of the metastatic lymph node ratio in patients with gastric cancer. World J Surg 36: 1096-1101, 2012.

17. Wang X, Appleby DH, Zhang X, Gan L, Wang JJ and Wan F: Comparison of three lymph node staging schemes for predicting outcome in patients with gastric cancer. Br J Surg 100: 505-514, 2013.

18. Wang HM, Huang CM, Zheng CH, et al: Tumor size as a prognostic factor in patients with advanced gastric cancer in the lower third of the stomach. World J Gastroenterol 18: 5470-5475, 2012.

19. Tokunaga M, Ohyama S, Hiki N, et al: Investigation of the lymphatic stream of the stomach in gastric cancer with solitary lymph node metastasis. World J Surg 33: 1235-1239, 2009.
20. Han KB, Jang YJ, Kim JH, et al: Clinical significance of the pattern of lymph node metastasis depending on the location of gastric cancer. J Gastric Cancer 11: 86-93, 2011.

21. Blum MA, Takashi T, Suzuki A and Ajani JA: Management of localized gastric cancer. J Surg Oncol 107: 265-270, 2013.

22. Okines A, Bang YJ and Cunningham D: Accomplishments in 2008 in the management of localized gastric cancer. Gastrointest Cancer Res 3: S48-S52, 2009.

23. Kasakura Y, Mochizuki F, Wakabayashi K, Kochi M, Fujii M and Takayama T: An evaluation of the effectiveness of extended lymph node dissection in patients with gastric cancer: a retrospective study of 1403 cases at a single institution. J Surg Res 103: 252-259, 2002.

24. Li C, Oh SJ, Kim S, et al: Macroscopic Borrmann type as a simple prognostic indicator in patients with advanced gastric cancer. Oncology 77: 197-204, 2009.

25. Wu LL, Liang H, Wang XN, Liu XY and Han T: Clinical characteristics of 103 lymph node metastasis in advanced proximal gastric cancer. Zhonghua Wei Chang Wai Ke Za Zhi 13: 590-593, 2010 (In Chinese)

26. Wang JB, Huang CM, Lu HS, et al: Efficacy of combined splenectomy in proximal gastric cancer with No. 10 lymph node metastasis. Chin J Gastrointest Surg 12: 121-125, 2009 (In Chinese).

27. Shin SH, Jung H, Choi SH, et al: Clinical significance of splenic hilar lymph node metastasis in proximal gastric cancer. Ann Surg Oncol 16: 1304-1309, 2009.

28. Maruyama K, Sasako M, Kinoshita T, Sano T, Katai H and Okajima K: Pancreas-preserving total gastrectomy for proximal gastric cancer. World J Surg 19: 532-536, 1995.

29. Hyung WJ, Lim JS, Song J, Choi SH and Noh SH: Laparoscopic spleen-preserving splenic hilar lymph node dissection during total gastrectomy for gastric cancer. J Am Coll Surg 207: e6-e11, 2008.

30. Cesta MF: Normal structure, function, and histology of the spleen. Toxicol Pathol 34: 455-465, 2006.

31. Mönig SP, Collet PH, Baldus SE, et al: Splenectomy in proximal gastric cancer: frequency of lymph node metastasis to the splenic hilus. J Surg Oncol 76: 89-92, 2001.

32. Li C, Kim S, Lai JF, et al: Solitary lymph node metastasis in gastric cancer. J Gastrointest Surg 12: 550-554, 2008. 